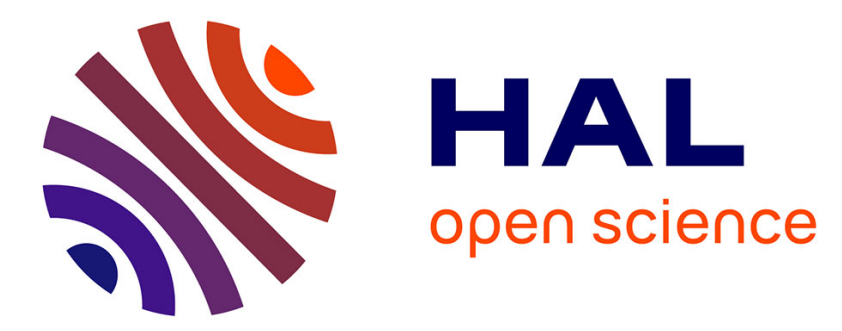

\title{
Atypical phonological processing impairs written word recognition in children with cochlear implants
}

Sophie G Bouton, Pascale Colé, Willy Serniclaes, Lynne G Duncan, Anne-Lise

G Giraud

\section{- To cite this version:}

Sophie G Bouton, Pascale Colé, Willy Serniclaes, Lynne G Duncan, Anne-Lise G Giraud. Atypical phonological processing impairs written word recognition in children with cochlear implants. Language, Cognition and Neuroscience, 2015, 10.1080/23273798.2014.1002796 . hal-01471061

\section{HAL Id: hal-01471061 \\ https://hal-amu.archives-ouvertes.fr/hal-01471061}

Submitted on 27 Feb 2017

HAL is a multi-disciplinary open access archive for the deposit and dissemination of scientific research documents, whether they are published or not. The documents may come from teaching and research institutions in France or abroad, or from public or private research centers.
L'archive ouverte pluridisciplinaire HAL, est destinée au dépôt et à la diffusion de documents scientifiques de niveau recherche, publiés ou non, émanant des établissements d'enseignement et de recherche français ou étrangers, des laboratoires publics ou privés. 


\title{
Atypical phonological processing impairs written word recognition in children with cochlear implants
}

\author{
Sophie Bouton ${ }^{\mathrm{a} *}$, Pascale Coléb, Willy Serniclaes ${ }^{\mathrm{c}, \mathrm{d}}$, Lynne G. Duncan ${ }^{\mathrm{e}}$ and Anne-Lise Giraud ${ }^{\mathrm{a}}$ \\ ${ }^{a}$ Department of Neuroscience, Campus Biotech, Geneva, Switzerland; ${ }^{b}$ Laboratory of Cognitive Psychology (UMR 7290), Aix-Marseille \\ University, Marseille, France; ${ }^{c}$ Laboratory of Psychology of Perception (UMR 8158), CNRS and Paris-Descartes University, Paris, \\ France; ${ }^{d}$ Unité de recherche en Neurosciences Cognitives (UNESCOG), Université Libre de Bruxelles, Brussels, Belgium; ${ }^{e}$ School of \\ Psychology, University of Dundee, Dundee, Scotland, UK
}

(Received 20 June 2014; accepted 21 December 2014)

\begin{abstract}
Children equipped with cochlear implant (CI) do not achieve similar levels of word recognition as typical hearing (TH) children, but it is unclear whether the reading deficit results from less accurate phonological representations, atypical reading procedures, or both. Phonological representations are crucial for reading acquisition in an alphabetic writing system, but CI users learn to read without having achieved the same level of speech perception as TH children. In this behavioural study, we addressed whether word reading in children using a CI $(n=25)$ is as strongly anchored in phonological operations as in TH children, matched for both chronological age $(n=25)$ and reading experience $(n=25)$. Using auditory phoneme perception tasks, we confirmed that children with a CI performed less accurately than TH children. When further tested for visual word recognition, CI users applied the same basic reading procedure as TH children, i.e., they read pseudowords through phonological decoding and irregular words through orthographic coding. Finally, using a visual lexical task where subjects had to decide whether pseudowords were or not real words, we observed that CI users rejected word homophones as accurately as TH children, but performed less well than TH controls for rejecting nonhomophones pseudowords. Preserved performance for homophones but not for non-homophones relative to controls suggests that children using a CI compensate for defective phonological processing by relying on lexical representations. Altogether, this series of studies allows us to propose that the reading operations in children with a CI are similar in nature as in $\mathrm{TH}$ children, yet constrained by less reliable phonological representations.
\end{abstract}

Keywords: phonology; reading; word recognition; development; cochlear implant

The mapping of graphemes, i.e., sub-lexical written units, to corresponding phonemes, i.e., sub-lexical speech units, is an essential process of reading acquisition. It strongly relies on the quality of the learner's speech perception (Burnham, 2003; Chiappe, Chiappe, \& Siegel, 2001; Hoonhorst et al., 2011) and more generally on phonological processing (Banai et al., 2009; Bogliotti, 2003; Dillon, de Jong, \& Pisoni, 2012; Hornickel, Anderson, Skoe, Yi, \& Kraus, 2012; Ramus, 2003; Snowling, 2000; Vellutino, Fletcher, Snowling, \& Scanlon, 2004; Wible, Nicol, \& Kraus, 2004). While typical hearing (TH) children learn to read once they already master oral language, congenitally deaf children with cochlear implants (CI) start reading with a lower level of language proficiency and poorer phonemic representations (Bouton, Serniclaes, Bertoncini, \& Colé, 2011, 2012; Geers, Brenner, \& Davidson, 2003; Goldsworthy, Delhorne, Braida, \& Reed, 2013; Havy, Nazzi, \& Bertoncini, 2013; Medina \& Serniclaes, 2009; Tye-Murray, Spencer, \& Gilbert-Bedia, 1995).

There are two potential reasons for atypical speech perception in children who use CI. First, they receive the implant after a variable period of hearing deprivation, which delays language acquisition, and likely results in weakened connections between primary and association cortices (Sharma, Campbell, \& Cordon, 2014). Second, implants deliver imperfect acoustic input (Dorman, Loizou, Spahr, \& Maloff, 2002; Shannon, Zeng, Kamath, Wygonski, \& Ekelid, 1995; Xu \& Zheng, 2007). Even in the ideal case, where all electrodes are activated after surgery, CIs encode less acoustic details than a physiological cochlea (Loizou, 1998, 2006). There is a drastic decrease in spectral resolution, as about 3000 inner hair cells are replaced by about 20 electrodes, of which often only a few are simultaneously activate. Even though temporal information (Friesen, Shannon, \& Cruz, 2005) is rather well transmitted, degraded acoustic cues impacts speech recognition in CI users (Friesen, Shannon, Baskent, \& Wang, 2001; Gnansia et al., 2014).

In typical developmental conditions, speech perception requires the perceptual mapping of continuous acoustic signals to discrete linguistic representations, e.g., phonemes, syllables, words. To each one of these building blocks, e.g., a phoneme, may correspond a variety of 
acoustic realisations depending on various factors such as the speaker, co-articulation, etc. The acoustic-to-linguistic mapping hence implies that speech sounds that can perceptually be discriminated may be assigned to the same or to different speech phonemic representational category/ies, which are subsequently used for phoneme/ grapheme mapping when learning to read. In TH children, phonemic categories emerge early in life (Burnham, Earnshaw, \& Clark, 1991; Hazan \& Barrett, 2000; Hoonhorst et al., 2011) and continue refining during the first six years of life (Bernstein, 1983; Hazan \& Barrett, 2000; Nittrouer, 1992, 1996, 2002; Nittrouer \& Miller, 1997; Slawinski \& Fitzgerald, 1998), with flexible boundaries up to the beginning of adolescence (Burnham et al., 1991; Hazan \& Barrett, 2000; Medina, Hoonhorst, Bogliotti, \& Serniclaes, 2010).

In congenitally deaf children using a CI, however, phonemic representations likely develop with a different dynamics. Speech perception could suffer from delays in building the relevant phonemic representations, or from difficulties in stabilising their boundaries (Bouton et al., 2012), and this could in turn affect the reading trajectory of children using a CI (Berent, Lennertz, \& Balaban, 2012; Bogliotti, Serniclaes, Messaoud-Galusi, \& SprengerCharolles, 2008; Noordenbos, Segers, Serniclaes, Mitterer, \& Verhoeven, 2012; Serniclaes, Van Heghe, Mousty, Carré, \& Sprenger-Charolles, 2004; Vandermosten et al., 2011). Accordingly, both a higher dispersion in reading ability and an absence of consistent pattern of reading acquisition are observed (Archbold et al., 2008; Dillon et al., 2012; Dunn et al., 2014; Fagan, Pisoni, Horn, \& Dillon, 2007; Geers, 2003; Harris \& Terlektsi, 2011; Spencer \& Tomblin, 2009; Vermeulen, Van Bon, Schreuder, Knoors, \& Snik, 2007).

To address whether the origin of delays and variability in reading trajectory in children with a $\mathrm{CI}$ is limited to difficulties in phonological processing, or whether it also reflects abnormal reading procedures, we carried out three experiments in a population of 100 French-speaking children, including subjects with a CI and three groups of control children matched for age, duration hearing exposure or reading experience. In the first experiment, we addressed the status of phonological representations in children using a CI (Bouton et al., 2012), by exploring the ability to identify a given speech sound and to discriminate between speech sounds. The second experiment involved reading aloud pseudo- and irregular words to explore phonological decoding and orthographic coding, respectively (Harm \& Seidenberg, 2004; Ziegler, Perry, \& Zorzi, 2014). Typically, pseudowords are read more slowly than irregular words, indicating a grapheme-tophoneme phonological decoding procedure to decipher pseudowords and a more direct access to orthographic representations when reading irregular words (SprengerCharolles, Colé, Béchennec, \& Kipffer-Piquard, 2005; Sprenger-Charolles, Colé, \& Serniclaes, 2006). The third experiment used the pseudohomophone effect to investigate the automaticity of phonological access during a lexico-orthographic decision (Ziegler, Jacobs, \& Klüppel, 2001; Ziegler, Van Orden, \& Jacobs, 1997). Pseudohomophones are pseudowords sounding like real words, e.g., chokolate. They are typically harder to reject in a lexical decision task than other pseudowords, e.g., chopolate. Because they are phonologically identical to real words, e.g., chocolate, pseudohomophones activate a lexical entry, slowing down the rejection process. This delay reflects the conflict between the pseudoword's phonology that is consistent with a real word, and its orthography signalling that no such word exists (Goswami, Ziegler, Dalton, \& Schneider, 2001; Sprenger-Charolles, Siegel, Béchennec, \& Serniclaes, 2003).

Using these three experiments (Figure 1) we expect to be able to (1) confirm a reading disorder in children with a CI, and (2) distinguish whether the reading disorder only reflects a selective deficit of phonological representations (Experiment 1) or is associated with atypical reading routines, e.g., atypical access to phonological information (Experiment 2), or atypical interactions between phonological and orthographic procedures (Experiment 3).

\section{Methods}

\section{Participants}

Twenty-five children using a CI (11 boys and 14 girls, age $7 ; 11$ to $11 ; 6$ years;months) were recruited from grades 2 to 4. These children also participated in a previously published study (Bouton et al., 2012). Parents gave informed consent to the child's participation in the study. All children had bilateral congenital profound deafness, and had been using a CI since the age of 22-42 months (mean: 31 months) for at least five years. Only one child had deaf parents. Three implant types were included: Clarion (Advanced Bionics), Nucleus 24 device (Cochlear Corporation) and Digisonic (Neurelec). Before implantation, all children used conventional hearing aids and were still using them (sometimes only occasionally) in their non-implanted ear. The number of active electrodes ranged between 12 and 24, representing $71-100 \%$ of active electrodes (relative to the total number of contacts that varies with the CI brand). Fourteen of the 25 children used cued speech, and 11 of the remaining children relied solely on speech to communicate. Nineteen of the 25 children were enrolled in mainstream classes and 6 children were in a spoken language classroom in a deaf school (i.e., special education with oral instruction). Clinical and demographic data are summarised in Table 1.

Seventy-five TH children (33 boys and 52 girls) were recruited from five kindergarten and elementary schools. They all met the following criteria: (1) native French speakers, (2) no history of auditory, language or reading disorders and (3) reading score within the normal range. 


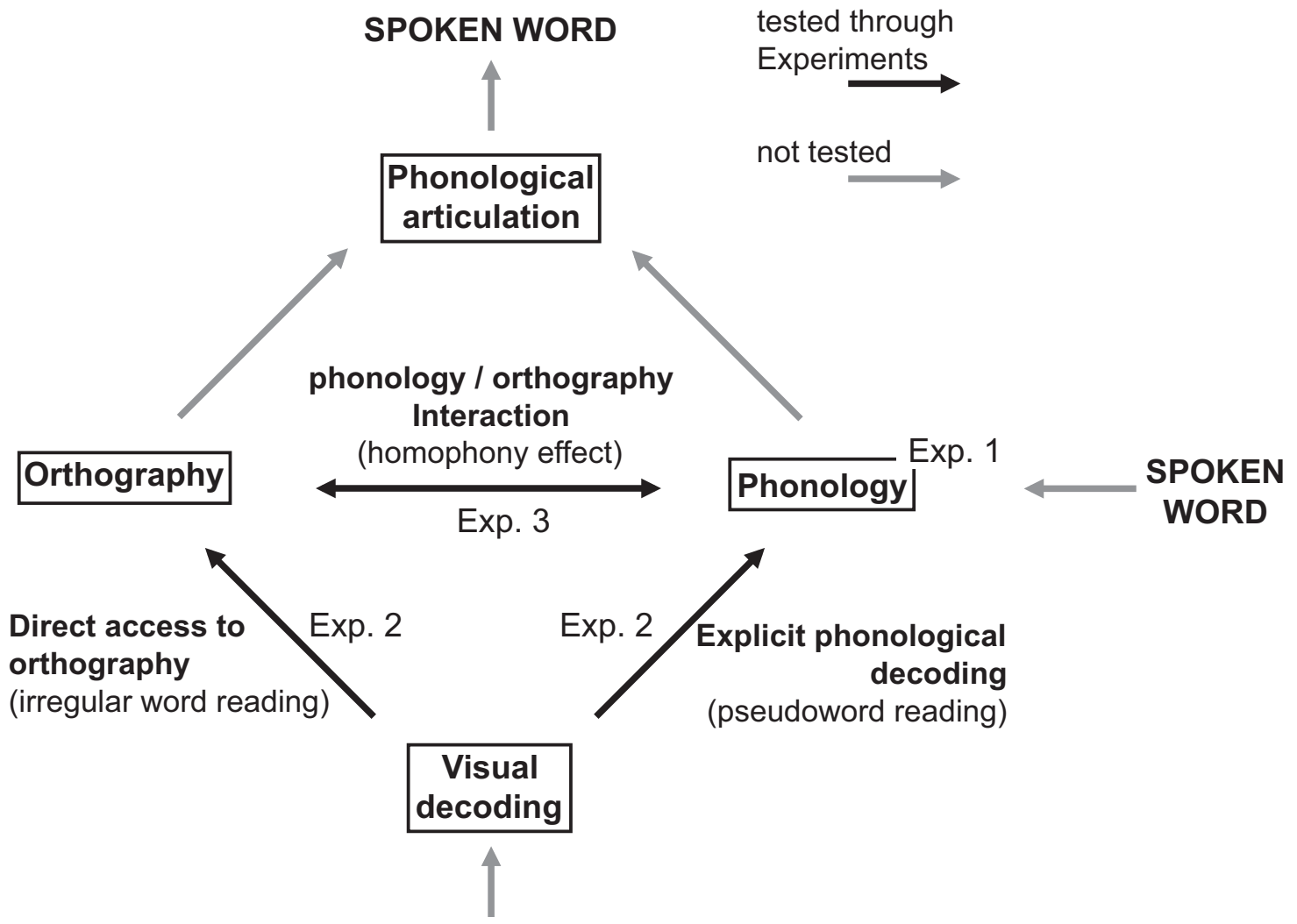

WRITTEN WORD

Figure 1. Summary of procedures involved in typical reading. Experiment 1 tests for the integrity of phonological representations. Experiment 2 separately explores the use of phonological decoding and orthographic coding in reading. Experiment 3 investigates how phonological representations influence orthographic coding during reading. The central hypothesis is that phonological representations are impaired, and three hypotheses are further tested here: (1) the phonological/orthographic routes of reading are involved in a typical way; and (2) the use of phonological/orthographic routes is atypical: orthographic coding is dominant for reading in children using CI.

Reading scores were obtained from the Alouette test (Lefavrais, 1967), a French reading test standardised to measure decoding skills in children aged 5-14 years. This test is routinely used in computerised test batteries such as EVALEC (Sprenger-Charolles et al., 2005) and BELEC (Mousty \& Leybaert, 1999). Participants are invited to read aloud a meaningless text with unrelated sentences. A reading score called 'reading age' is calculated by adding the time taken to read (in seconds) to the number of errors. This composite score hence takes into account both accuracy and speed of word recognition, but not reading comprehension.

The TH subjects formed three control groups. One control group was used in the first experiment, and the two others served as a double control in the two other experiments. In the first experiment exploring phonological perception, the control group comprised 25 children matched with the 25 children with a CI for duration of hearing exposure. Since CI children present an auditory deprivation period, these control children were hence overall younger than the CI users (see Table 2). In the second and third experiments that investigated reading procedures, there were two control groups, each made of 25 children matched with the CI kids for chronological age and reading age (see Table 2). All parents gave informed consent to the child's participation in the study.

\section{Experiment 1: phoneme perception}

We assessed the level of phoneme perception using two tasks: a discrimination task and an identification task. In both cases, the stimuli were auditory words taken from the Manulex database (Lété, Sprenger-Charolles, \& Colé, 2004). All stimuli were recorded in a soundproof room, while an adult female read aloud a list of words with a 2-s pause between each word. The speaker was instructed to speak clearly, calmly and with the same prosodic structure for each word. Stimuli were natural realisations of words with cross-syllable co-articulation. Productions were digitised at a resolution of 32 bits and a sampling rate of $44.1 \mathrm{kHz}$. Acoustic analyses were performed using the Praat speech analysis software (Boersma \& Weenink, 2000), and a custom script was used to identify word boundaries on the basis of intensity thresholds 
Table 1. Clinical and demographic characteristics of children with CIs.

\begin{tabular}{|c|c|c|c|c|c|c|c|c|}
\hline $\operatorname{Age}^{a, b}$ & $\begin{array}{l}\text { Implantation } \\
\text { age }^{\mathrm{b}}\end{array}$ & $\begin{array}{l}\text { Listening } \\
\text { age }^{\mathrm{b}}\end{array}$ & $\begin{array}{l}\text { Reading } \\
\text { age }^{b, c}\end{array}$ & Grade & $\begin{array}{l}\text { Type of } \\
\text { school }\end{array}$ & Language & Device & $\begin{array}{c}\text { Percentage of active } \\
\text { electrodes }\end{array}$ \\
\hline $9 ; 3$ & $3 ; 5$ & $5 ; 10$ & $6 ; 9$ & 2 & SE & $\mathrm{O}$ & N. & 100 \\
\hline $9 ; 2$ & $2 ; 1$ & $7 ; 1$ & $6 ; 9$ & 2 & Mainst. & O. $+\mathrm{CS}$ & N. & 100 \\
\hline $8 ; 1$ & $2 ; 6$ & $5 ; 7$ & $7 ; 9$ & 2 & Mainst. & O. + CS & N. & 79 \\
\hline $9 ; 9$ & 2 & $7 ; 9$ & $6 ; 7$ & 2 & SE & O. $+\mathrm{CS}$ & N. & 71 \\
\hline 8 & 3 & 5 & $6 ; 7$ & 2 & Mainst. & O. & N. & 79 \\
\hline $11 ; 6$ & $3 ; 6$ & 8 & $7 ; 5$ & 4 & SE & O. & N. & 87.5 \\
\hline $8 ; 1$ & $1 ; 6$ & $6 ; 7$ & $8 ; 5$ & 2 & Mainst. & O. $+\mathrm{CS}$ & N. & 100 \\
\hline $7 ; 6$ & 2 & $5 ; 6$ & $7 ; 1$ & 2 & Mainst. & $\mathrm{O}$. & N. & 92 \\
\hline $9 ; 3$ & $3 ; 4$ & $5 ; 11$ & $7 ; 9$ & 3 & Mainst. & O. $+\mathrm{CS}$ & N. & 92 \\
\hline $9 ; 8$ & $1 ; 1$ & $8 ; 7$ & $8 ; 3$ & 4 & Mainst. & O. $+\mathrm{CS}$ & D. & 83 \\
\hline $8 ; 6$ & $3 ; 6$ & 5 & $7 ; 9$ & 2 & Mainst. & O. $+\mathrm{CS}$ & N. & 96 \\
\hline $8 ; 6$ & $3 ; 2$ & $5 ; 4$ & $8 ; 5$ & 2 & Special & O. $+\mathrm{CS}$ & N. & 79 \\
\hline $7 ; 11$ & $2 ; 1$ & $5 ; 10$ & 8 & 2 & Mainst. & O. $+\mathrm{CS}$ & N. & 92 \\
\hline $8 ; 2$ & $1 ; 1$ & $7 ; 1$ & $7 ; 4$ & 2 & Mainst. & O. $+\mathrm{CS}$ & C. & 100 \\
\hline $9 ; 7$ & 3 & $6 ; 7$ & 8 & 4 & $\mathrm{SE}$ & O. & N. & 96 \\
\hline 10 & $4 ; 6$ & $5 ; 6$ & $7 ; 6$ & 4 & Mainst. & O. $+\mathrm{CS}$ & N. & 87.5 \\
\hline $8 ; 9$ & 3 & $5 ; 9$ & $6 ; 9$ & 2 & Mainst. & O. & N. & 92 \\
\hline $9 ; 1$ & $3 ; 6$ & $5 ; 7$ & $7 ; 3$ & 2 & Mainst. & O. $+\mathrm{CS}$ & N. & 87.5 \\
\hline $9 ; 2$ & $2 ; 6$ & $6 ; 8$ & $7 ; 11$ & 3 & Mainst. & O. & N. & 79 \\
\hline $9 ; 9$ & $2 ; 10$ & $6 ; 11$ & $9 ; 4$ & 4 & Mainst. & $\mathrm{O}$. & C. & 83 \\
\hline 11 & $2 ; 10$ & $8 ; 1$ & $6 ; 9$ & 2 & SE & O. & N. & 100 \\
\hline $8 ; 11$ & $2 ; 5$ & $6 ; 6$ & $7 ; 10$ & 3 & Mainst. & O. $+\mathrm{CS}$ & N. & 83 \\
\hline $9 ; 6$ & $3 ; 5$ & $6 ; 1$ & $10 ; 2$ & 4 & Mainst. & $\mathrm{O}$ & N. & 96 \\
\hline $8 ; 6$ & $3 ; 2$ & $5 ; 4$ & $7 ; 11$ & 2 & Mainst. & O. $+\mathrm{CS}$ & N. & 96 \\
\hline $8 ; 7$ & 2 & $6 ; 7$ & $7 ; 11$ & 3 & Mainst. & O. & N. & 100 \\
\hline
\end{tabular}

CS, cued speech; AB, Advanced Bionics; SE, special education; Mainst., mainstream; N., Nucleus (cochlear); C., Clarion (AB); D., Digisonic (Neurelec); O., Oral.

${ }^{\mathrm{a} C h r o n o l o g i c a l ~ a g e ; ~}{ }^{\mathrm{b}}$ Ages are presented as years;months; ${ }^{\mathrm{b}}$ Listening age. Time since the child received CIs; ${ }^{\mathrm{c}}$ Reading age.

(Green, Beukelman, \& Ball, 2004). We then verified and manually adjusted the boundaries. Individual sound files starting and ending by a silent pause of $50 \mathrm{~ms}$ were created for each word and used for the experiment. The stimuli were presented through headphones (Beyerdynamic DT290), covering the ear and the microphone. Prior to the test sessions, we ensured that children were able to hear and repeat speech stimuli. We presented them with lists of 10 very frequent words (e.g. cat, leg, little, house, child, rat, bear, red, bike, snow) at low but comfortable level and asked them to repeat each word. We considered that the hearing level was comfortable if the children could repeat at least $80 \%$ of the words. When they repeated less than $80 \%$, another list was presented and the hearing level was increased by $5 \mathrm{~dB}$. The stimuli were presented in a quiet room at $70 \mathrm{~dB}$ Sound Pressure Levels (SPL) in 9 children, $75 \mathrm{~dB}$ SPL in 35 children and $80 \mathrm{~dB}$ SPL in 6 children.

In the discrimination and identification tasks, the stimuli were 68 consonant-vowel (CV) or CVC word pairs (AX format) comprising all the consonant features of French: voicing, nasality, manner and place of articulation. Minimal pairs of words only differed in one consonant feature (place of articulation, voicing, manner and nasality). Pairs were divided into 34 different-word pairs (e.g., for the $/ \mathrm{b} /-/ \mathrm{p} /$ contrast, peach-beach), and 34 same-word pairs (beach-beach), presented with a 100-ms interval between each item. For the same-word pairs, the same exemplar of the word was repeated twice. In the discrimination task, we used a two-alternative forced choice, in which the subjects had to indicate whether the stimuli were identical or different. In the identification task, one word was presented on each trial, and children had to indicate whether a picture shown on the computer screen corresponded to the spoken word. Pictures were easyto-recognise black and white line drawing illustrations. In a pre-test session, $100 \%$ of pictures were correctly named by $\mathrm{TH}$ children of five years of age. The list of items is provided in Appendix 1.1.

The two tasks were performed in random order and all pairs were presented only once, each in random order. The discrimination and identification responses were converted into $d^{\prime}$ scores, reflecting the sensitivity to phonemic categories (Macmillan \& Creelman, 2005). For the discrimination task, we calculated $d^{\prime}$ in the usual way through a subtraction of hits (correct 'yes, the two sounds are different' responses) minus false alarms (incorrect 'no, the two sounds are not different' responses). For the identification task, hits are correct 'yes, sound and picture 
Table 2. Means (standard deviations) in CI and TH participants' hearing age, reading age and chronological age.

\begin{tabular}{lcccc}
\hline & CI & Hearing age controls & Reading age controls & Age-matched controls \\
\hline Age (chronological) & $9 ; 1(1 ; 1)$ & $6 ; 4(1 ; 2)$ & $7 ; 6(0 ; 6)$ & $9 ; 1(0 ; 9)$ \\
Hearing age & $6 ; 6(1 ; 1)$ & $6 ; 4(1 ; 2)$ & $7 ; 6(0 ; 6)$ & $9 ; 1(0 ; 9)$ \\
Reading age & $7 ; 6(0 ; 8)$ & $6 ; 4(1 ; 6)$ & $7 ; 6(0 ; 9)$ & $9 ; 1(1)$ \\
\hline
\end{tabular}

Note: Ages are presented as years;months.

match' responses, and false alarms are incorrect 'no, sound and picture do no match' responses. According to the detection theory, discrimination estimates the category for each stimulus and then allows for comparing category estimates (Macmillan \& Creelman, 2005), whereas identification assesses perceptual distances between stimuli, and their location relative to category boundaries (Iverson \& Kuhl, 1996; Macmillan \& Creelman, 1991).

\section{Experiment 2: phonological vs. orthographic reading procedure}

In the second experiment, we assessed how phonological and orthographic codes were involved during reading, using irregular word and pseudoword reading. Pseudoword reading, e.g., tagle, pectil, tests for the use of phonological decoding, and irregular word reading, e.g., sew, yacht, for the use of the orthographic coding (see Figure 1). French contains many irregular words that read different from the way they are spelled, e.g., femme, oignon, etc. We used lists of French regular and irregular words consisting of 36 items matched for length and bigram frequency (Content \& Radeau, 1988). The mean length was 5.6 letters $(\mathrm{SD}=1.6), 4.4$ phonemes $(\mathrm{SD}=$ 1.8), 1.7 syllables $(\mathrm{SD}=0.5)$ for pseudowords and 5.7 letters $(\mathrm{SD}=1.7), 4.1$ phonemes $(\mathrm{SD}=1.6)$, 1.6 syllables $(\mathrm{SD}=0.6)$ for irregular words $(t<1$ for all). Mean bigram frequency was $37(\mathrm{SD}=11.6)$ and $36(\mathrm{SD}=$ 13.3) for pseudowords and irregular words, respectively $(t<1)$. To optimise the measurement of reaction times, the items of each list were matched on initial grapheme/ phoneme (list of items in Appendix 1.2). The children were instructed to read aloud the item displayed in the centre of the screen as accurately and quickly as possible. We used a sound card to record the children's vocal responses, and measured response accuracy and reading onset latencies (stimulus onset to response onset). Correct responses were coded by 10 listeners, who had no daily contact with the CI users. After listening to each production, they noted the response without knowing the target word. Later, the experimenter compared targets and responses to calculate the percentage of correct responses for each child. Responses were rated correct when more than half of the judges quoted them as correct. Overall there was a good agreement among the judges $(K=.78)$.
As Experiment 2 involved reading aloud, we controlled for a possible influence of speech production difficulties in word recognition performance, by incorporating speech production scores (see Table in Appendix 2) as a covariate in the ANCOVA that tested for group differences in pseudoword and irregular word recognition (see Results section). Speech production was assessed using a picturenaming task where subjects were asked to name 40 pictures presented one at a time on a computer screen. The pictures/names were chosen to be familiar to the participants and frequent $(1.5 \%$, corresponding to a standard frequency index of 85 in MANULEX, Lété et al., 2004). Vocal responses were recorded, and independent judges determined response quality following the same procedure as for word reading.

\section{Experiment 3: interaction of phonological and orthographic procedures}

Finally, we assessed the automatic involvement of phonological decoding in reading, using a lexical decision task performed on misspelled written words. We examined the homophony effect, which assesses whether word decoding is influenced by phonological representations. We manipulated word misspelling to compare responses to pseudowords that are homophones of real words, e.g., wisard, with responses to control pseudowords that are not homophones of a real word, e.g., wilard. We selected 30 regular French words: 15 words were fillers and 15 words were used to build matched homophone and non-homophone pseudowords (items are listed in the Appendix 1.3). All source words were familiar to young children (spelled correctly by first graders at least $80 \%$ of the time, according to the standardised scale EOLE, Echelle d'acquisition en orthographe lexicale, Pothier \& Pothier, 2004). The words were frequent $(1.5 \%$, with a standard frequency effect of 85, Manulex, Lété et al., 2004). Homophones were created by changing one vowel, or one consonant in the middle of the basis word (e.g., wizard/wisard), and the same procedure was applied to create non-homophones (e.g., wizard/wilard). The items were matched between conditions for orthographic frequency (frequency of bigrams, Content \& Radeau, 1988). Their mean length was 5.2 letters $(\mathrm{SD}=0.6), 4.1$ phonemes $(\mathrm{SD}=0.7)$ and 1.8 syllables $(\mathrm{SD}=0.5)$ for homophones, and 5.0 letters $(\mathrm{SD}=0.6), 4.1$ phonemes 
$(\mathrm{SD}=0.7)$ and 1.8 syllables $(\mathrm{SD}=0.6)$ for nonhomophones $(t<1$ for all). To facilitate the detection of response latency, the items were balanced for initial grapheme/phoneme. The children were instructed to read silently the item displayed in the centre of the computer screen and indicate whether the item was a real word or not by pressing one of two differently coloured keys on the keyboard as accurately and quickly as possible.

\section{Data analyses}

We analysed the data using parametric statistics. We performed ANOVAs (details in Results section) followed by planned comparisons when applicable, and used Bonferroni corrections to correct for multiple comparisons (statistics toolbox, MATLAB, the Mathworks).

\section{Results}

\section{Phoneme perception}

We used a $2 \times 2$ repeated-measures ANOVAs on $d^{\prime}$ sensitivity scores with group (CI vs. hearing age controls) and task (discrimination vs. identification) as withinsubjects factors. We found a main effect of task $[F(1,96)=13.11, p<.001]$ and group $[(F(1,96)=$ 106.70, $p<.001]$ (Figure 2). Both identification and discrimination accuracy was reduced in children with a CI as they overall performed less well than TH children on each task (significant group effect, $p<.001$, red vs. grey bars on Figure 2). Importantly, there was no group $\times$ task interaction $(F<1)$, showing that the relation between identification and discrimination was preserved in the CI users group (dark vs. light bars on Figure 2). Joint alteration of discrimination and identification suggests that the difficulty in identification reflects a deficit at the sensory rather than category access/formation level. Overall children using CI acquired the ability to categorise phonemes, but made more phonemic confusions, and hence present with a deficit in identification and discrimination accuracy.

\section{Phonological vs. orthographic procedures}

Correct response rates (CRs) and response times (RTs) were analysed independently using $2 \times 3$ repeatedmeasures ANCOVAs with group (CI vs. age-matched controls vs. reading age controls) and lexicality (pseudowords vs. irregular words) as factors. We controlled for group differences in speech production by using word naming scores as a covariate of no-interest in the ANOVA (group effect for accuracy: $F(13,143)=6.85$, $p<.001$ and reaction times $F(13,143)=7.03, p<.001)$.

For CRs, we found a significant main effect of group $[F(2,143)=19.04, p<.001]$ and lexicality $[F(1,143)=$ $35.03, p<.001]$, and no significant interaction $[F(2,143)=$
$1.87, p>.10]$. Figure $3 \mathrm{~A}$ shows the mean reading scores for irregular words and pseudowords for each group. CRs were overall lower in children with a CI relative to controls $(p<.05$ for irregular words and $p<.001$ for pseudowords), but critically, this difference was due to lower performance to correctly decode pseudowords, while irregular words were accurately read. Although each group exhibited a lexicality effect $(p<.001$ for all groups), the accuracy difference between pseudo- and irregular words was similar in children with a CI and age-matched controls. Expectedly, this difference was larger in younger reading age controls (Figure $3 \mathrm{~B}$ ).

Figure $3 \mathrm{C}$ shows the mean latency for reading irregular and pseudowords. The ANOVA indicated a main effect of group and lexicality $[F(2,143)=8.47, p<.001 ; F(1,143)=$ $7.19, p<.001$, respectively] and no interaction $(F<1)$. The group effect was due to enhanced reading speed in age-matched controls relative to the younger reading age controls $(p<.01)$. The children who used a CI had intermediate latencies between the two control groups (no significant difference to either group, $p=.20$ ). Critically, the lexicality effect, showing that irregular words were read more rapidly than pseudowords, was present in all three groups (CI: $p<.01$; age-matched: $p<$ .05 ; reading age-matched: $p<.05$ ), yet was significantly enhanced in CI users (Figure 3D). This effect was due to prolonged decoding of pseudowords in these children, whereas irregular words were read at normal speed.

The reading task indicates that all groups applied the same basic procedures: pseudowords were read through phonological decoding, and irregular words through orthographic coding (normal lexicality effect). Nevertheless, across tasks, children with a CI made more errors

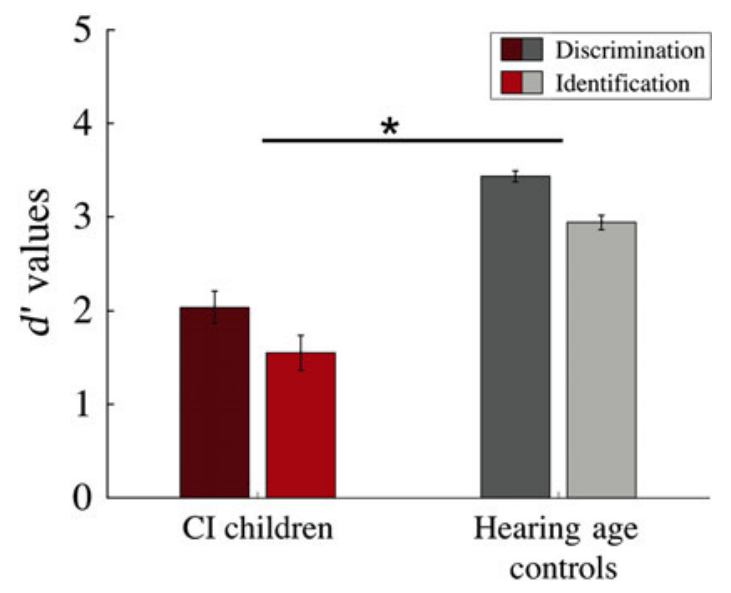

Figure 2. Experiment 1. Phoneme perception: mean CRs $\left(d^{\prime}\right)$ in discrimination and identification tasks in CI and hearing age controls. Hearing age controls performed better than CI users on both tasks (grey vs. red bars). Identification scores were lower than discrimination scores in both groups (dark vs. light bars), and there was no group $\times$ task interaction. All error bars indicate SEM. ${ }^{*} p<.001$. 
than TH children in pseudoword reading and read pseudowords more slowly.

\section{Interaction of phonological and orthographic procedures}

The next experiment used the homophony effect to address the influence of phonology on orthographic coding. CRs and RTs were analysed independently using $2 \times 3$ repeated-measures ANOVAs with group (CI vs. agematched controls vs. reading age controls) and homophony (homophones vs. non-homophones). We observed significant effects of group $[F(2,144)=4.2, p<.05]$ and homophony $[F(1,144)=55.29, p<.001]$ in the correct response scores and a significant interaction between the two factors $[F(2,144)=4.02, p<.05]$. Figure 4A shows the mean correct rejection of pseudowords for each group. Children who use a CI had similar lexical decision scores as reading age controls $(t<1)$ but lower than age-matched children $(p<.01)$. Each group exhibited the homophony effect (CI users: $p<.01$; age-matched controls: $p<.001$; reading age controls: $p<.001$ ). However, the difference between homophones and non-homophones was larger in control than children with a CI (reading age-matched $p<.001$; age-matched $p<.01$, respectively; Figure 4B). $\mathrm{CI}$ and $\mathrm{TH}$ children had similar (normal for 4th grade) scores for decoding homophone pseudowords. Critically, the reduced homophony effect in CI users was accounted
A

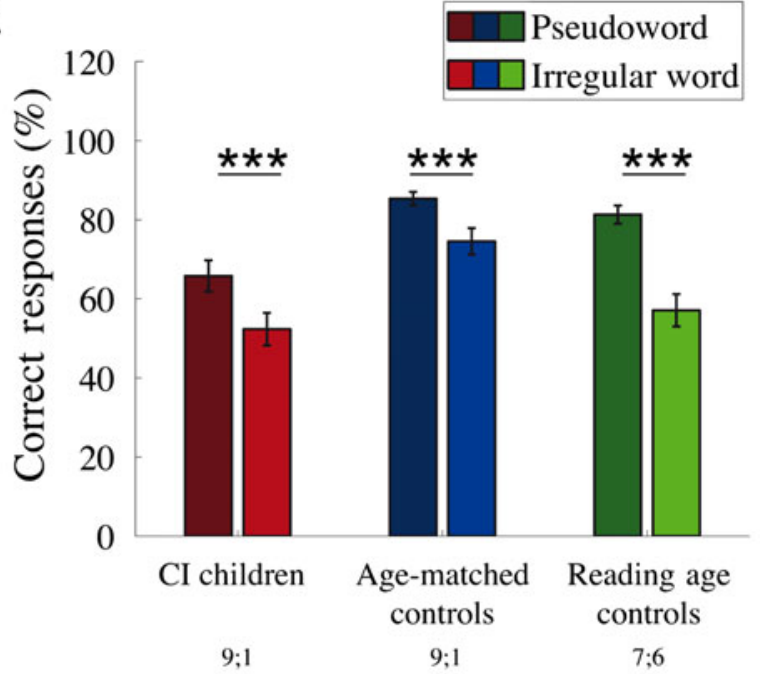

B

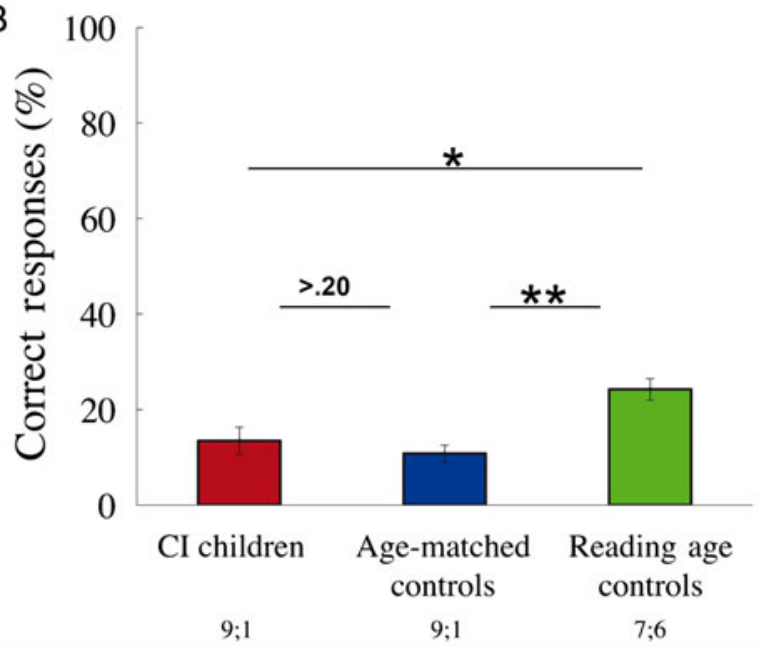

C

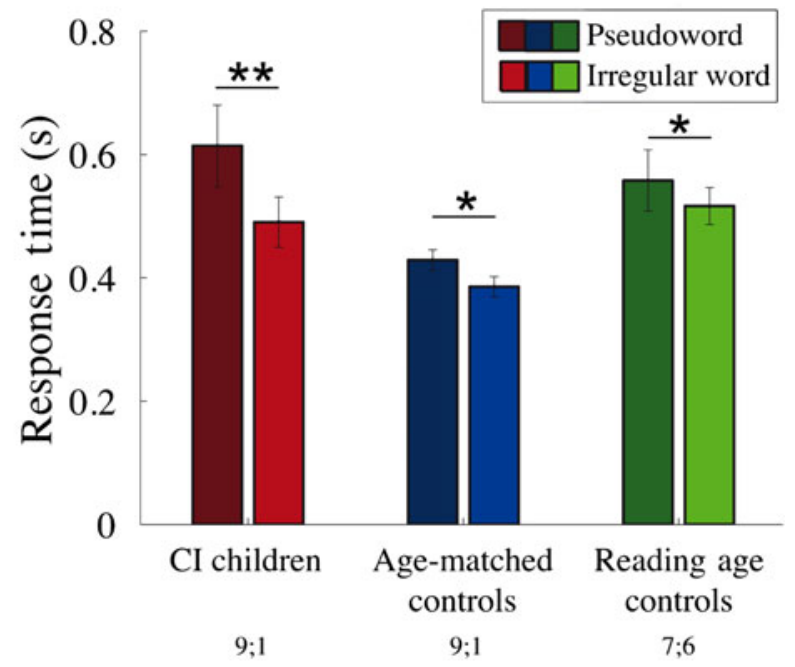

D

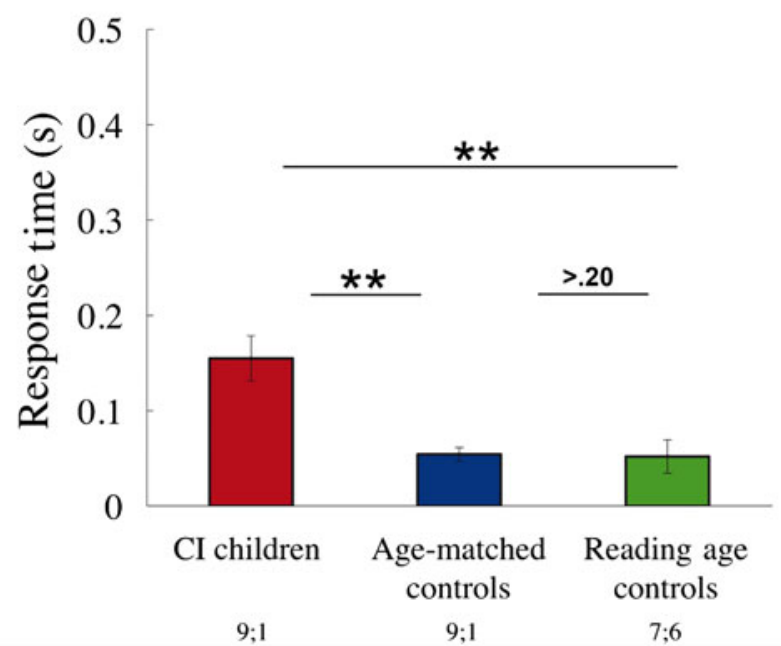

Figure 3. Experiment 2. Irregular words and pseudowords reading. Data are presented in children using CI, TH controls matched for age, and for reading age. Left panels: correct responses (\%); right panels: response time (s). Top panels: raw values for each condition and each group; bottom panels: delta values between conditions - pseudowords minus irregular words - for each group. All error bars indicate SEM. ${ }^{*} p<.05 ;{ }^{* *} p<.01 ; * * * p<.001$. (A and C) Each group exhibited a lexicality effect. (B) CI users showed a similar lexicality effect as age-matched controls on accuracy. (D) CI users showed a bigger lexicality effect than TH children on reaction times (they were slower for decoding pseudowords). 

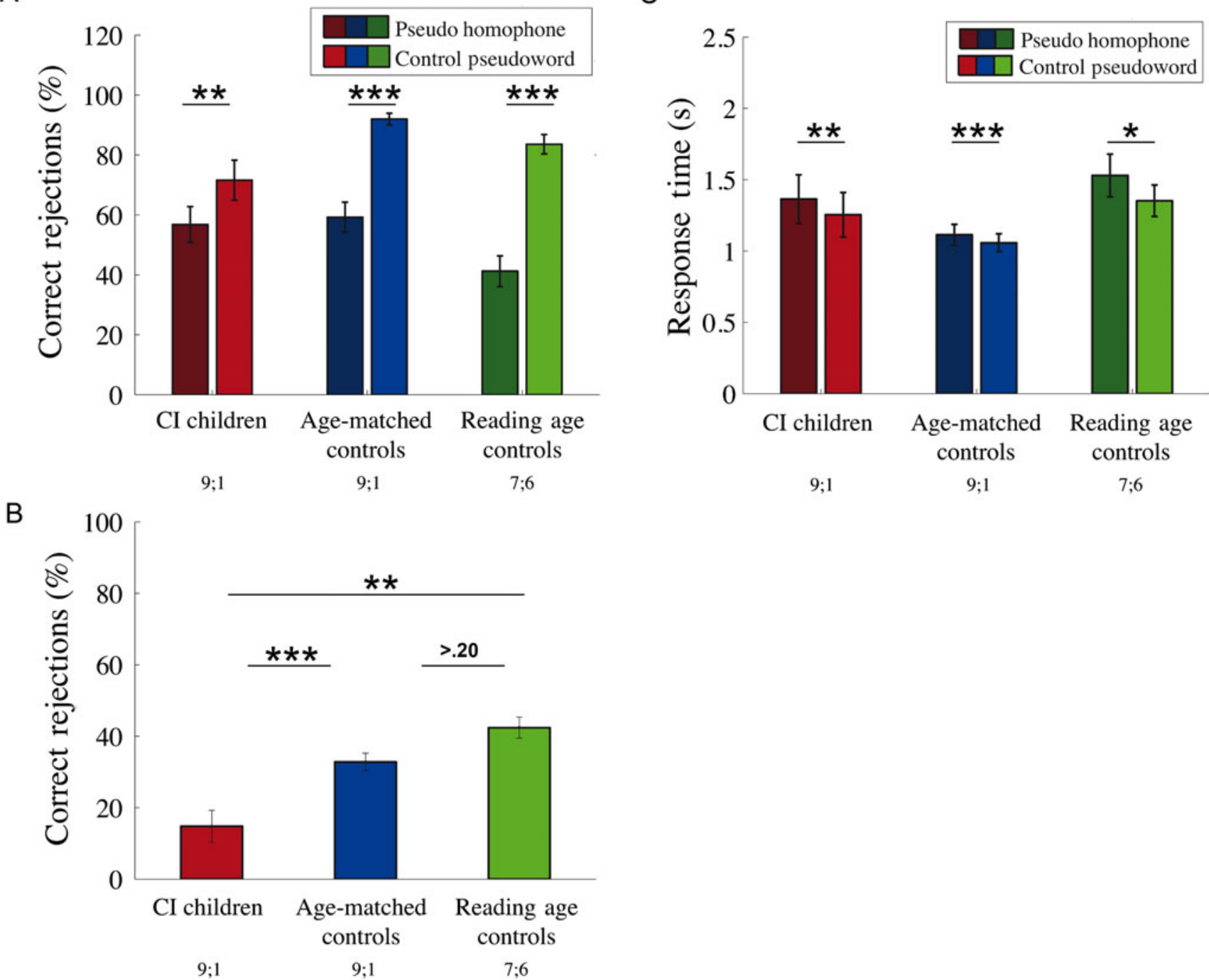

Figure 4. Experiment 3. Performance in a lexical decision task using homophone and non-homophone pseudowords. Data are presented for children using $\mathrm{CI}$ and $\mathrm{TH}$ children matched for chronological age, and for reading age. Left panels: correct responses (\%); right panels: response time (s). Top panels: raw values for each condition and each group; bottom panels: delta values between conditions non-homophone pseudowords minus homophones - for each group. All error bars indicate SEM. ${ }^{*} p<.05 ; * * p<.01 ; * * * p<.001$. (A and C) All groups exhibited a homophony effect. (B) Children with a CI showed a lower homophony effect than TH children on accuracy.

for by lower scores for non-homophones $(p<.001)$, indicating that children with a CI used phonological representations less automatically than $\mathrm{TH}$ controls when reading words (as shown in Experiment 2). Despite a reduced performance with non-homophone pseudowords, children with CIs displayed a normal-range performance on homophone pseudowords, suggesting a stronger-thannormal reliance on orthographic representations when performing this task. Figure 4C illustrates the mean reaction times (in seconds) for non-homophones and homophones for each group. There was no group effect $[F(2,144)=1.24, p>.10]$, but a significant homophony effect $[F(1,144)=8.29, p<.01$, indicating that all groups categorised non-homophones more rapidly than homophones $(p<.05$, for children with a CI; $p<.01$, for agematched; $p<.001$, for reading age-matched) (Figure 3D). There was no homophony $\times$ group interaction $(F<1)$ in reaction times.

\section{Discussion}

The current findings globally confirm a moderate word recognition deficit in deaf children who use a CI. They made more errors than their $\mathrm{TH}$ peers on both phonemic identification and discrimination (Figure 5), while preserving the same relationship between identification and 


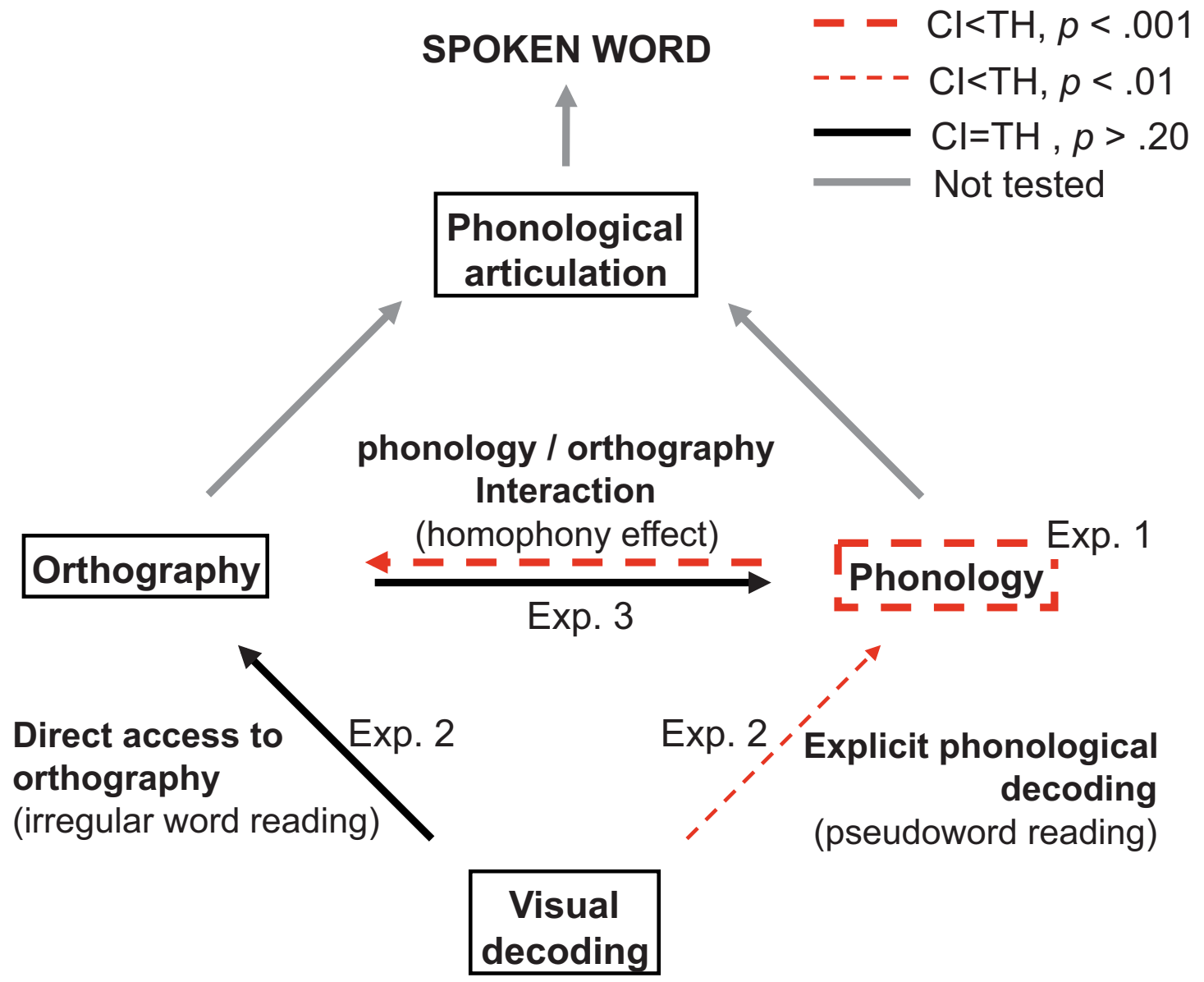

\section{decoding}

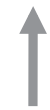

\section{WRITTEN WORD}

Figure 5. Summary of results. Experiment 1 showed that phonemic categories are formed but less accurate in deaf children with CI relative to TH hearing subjects of identical hearing age. Experiment 2 showed that children with CI used orthographic coding to read irregular words as efficiently as controls, but used less well than TH controls matched for age and reading age the phonological decoding procedure to read pseudowords. Experiment 3 shows a weaker homophony effect in children with CI than in TH controls. This effect was accounted for by a reduced correct rejection rate in deaf children, reflecting a less efficient use of phonological representations when categorising non-homophone pseudowords. Given the reduced rejection rate for non-homophone pseudowords, the normal-range rejection rate for homophone pseudowords likely reflects orthographic compensation.

discrimination as those $\mathrm{TH}$ children who had equivalent hearing experience. Similar results are observed in adults CI users, who classify phoneme with less category discrimination and identification accuracy (Iverson, 2003; Lane et al., 2007). The current study shows that children CI users have a global deficit in phoneme perception, but that their ability to categorise phonemes given their phonemic discrimination capacity is intact. Presumably, lower identification performance follows from their reduced ability to discriminate speech sounds. Atypical phonological representations in children using CIs are expected because phonological processing is limited by the quality of the input coming for the implant, which only imperfectly transmits the spectro-temporal cues. Poorer phonemic perception accuracy might also to some extent result from insufficient exposure to speech in the first year of life. The children enrolled in this study received their CI between 1.5 and 3.5 years, and as phonemic categories develop from birth in typically developing children (Hoonhorst et al., 2009), their central auditory system may already have reorganised in a way that limits an optimal benefit from the implant (Kral \& Sharma, 2012; Sharma, Dorman, \& Kral, 2005). Alternatively, it might be that the early auditory deficit cannot fully be compensated for within the timeframe during which the phonological system remains plastic (Medina 
et al., 2010). Overall, poorer phonological processing in children who use a CI presumably reflects a combination of hearing deprivation and degraded auditory input (Dorman et al., 2002; Shannon et al., 1995; Xu \& Zheng, 2007), and this might place some constrains on the way the children learn to read (Kraus \& Anderson, 2013). As this is also the case for the phonological deficit in dyslexia (Ahissar, 2007; Ramus \& Szenkovits, 2008; Boets et al., 2013), it remains unclear whether the difficulties experienced by children using CIs are limited to degraded phonological representations or whether the ability to access them is also impaired.

Irrespective of whether phonological representations and/or access are affected, weaker phonological processing could, as in dyslexia, be accompanied by orthographic difficulties (Hasko, Groth, Bruder, Bartling, \& Schulte-Körne, 2013), or on the contrary, be compensated for by orthographic knowledge if the latter normally develops. Connectionist models of reading (as those developed by Perry, Ziegler, \& Zorzi, 2007, 2010; Harm \& Seidenberg, 1999, 2004) posit that finely tuned phonological representations are necessary for efficient phonological decoding, and that this process in turn shapes word-specific orthographic representations used for orthographic coding (Share, 1995, 1999; Sprenger-Charolles et al., 2003). Once reading is acquired the two pathways could flexibly be used for reading depending on context. Typically, frequent words are read without phonological decoding, while new words require explicit grapheme/phoneme conversion and phonological analysis (Ripamonti et al., 2014). Experiments 2 and 3 explore the interaction between phonological decoding and orthographic coding during reading. In particular, they allow for testing whether phonological decoding constitutes a bottleneck that prevents correct orthographic processing in children who use CIs, or whether orthographic processing can correctly be achieved and even supplement deficient phonological processing.

The results of Experiment 2 indicate that both CI and $\mathrm{TH}$ children rely on the same reading procedures: irregular words are read more quickly, i.e., via direct orthographic coding, than pseudowords, i.e., via indirect phonological decoding. However, although children with CI had normal-range performance for irregular words, they read pseudowords less accurately and quickly than TH controls. In summary, the procedures deaf children with CI employ to read words appear qualitatively similar to those used by $\mathrm{TH}$ children, but when reading is unconstrained by orthography and lexical representations (pseudoword reading), the performance deteriorates. This very specific deficit likely reflects the difficulty CI users experience in phonological processing, rather than difficulties with orthography.

The reading models depicted by Harm and Seidenberg (2004) and more recently by Ziegler et al. (2014) assume that phonological decoding and orthographic coding are not independent. In Experiment 3, we assessed their interplay in children with and without CI using the pseudo-homophone effect, which quantifies the amount of phonological influence occurring during a lexical task performed on written words. To correctly perform the word/non-word lexical task, children must achieve correct phonological decoding of written pseudowords and evaluate the correspondence between the read item and the orthographic representations activated in their lexicon. Because the way words sound interfere with the orthographic procedure when reading, homophone pseudowords constructed by altering the orthography of real words are in principle harder to reject as existing words than regular pseudowords.

Experiment 3 confirmed that homophones generated more errors and were rejected more slowly than nonhomophones by children of all three groups. However, the homophony effect was reduced in deaf children with CI relative to both control groups. This effect is unlikely to be due to less developed orthographic knowledge among CI users, because we derived homophones from words that could correctly be spelled by $80 \%$ of first graders. As the mean reading level of the participants who use a CI ranged from second to fourth grade, we can consider orthographic representations for the selected words firmly established. Moreover, deaf children with CI had similar homophone scores as TH controls of the same age, whose mean reading level corresponds to fourth grade. Importantly, the smaller homophone effect in CI users was due to a lower performance on non-homophone pseudowords, which cannot be accounted for by a lexical memory effect.

Interestingly, the reduced homophony sensitivity in CI users was accounted for by enhanced difficulties to decide whether non-homophone pseudowords were words, which presumably reflects their difficulties at the phonological level (Figure 5, Experiment 2). By comparison, the normal-like performance they exhibited on pseudowords that sound like real words (Figure 5, Experiment 3 black arrow) suggests a stronger-than-normal reliance on orthographic representations to decide when written items are real words. The underlying hypothesis of Experiment 3 is that participants attempt to find a correspondence between the pattern activated in their phonological lexicon and an existing word memorised in their orthographic lexicon. The results suggest that such a compensation is used for homophone pseudowords by children with a CI (Figure 5, Experiment 3, red dotted arrow). We hence propose that in CI users, phonological decoding difficulties are partly compensated for by direct access to meaning from visuoorthographic input. This hypothesis is also supported by functional neuroimaging studies showing that adults CI users can by-pass classical phonological steps when performing linguistic tasks from written material (Lazard, Lee, Truy, \& Giraud, 2013). 
Altogether, the current findings indicate that speech perception in children implanted before the age of 3.5 years affords normal development of reading. They further show that deaf children with CIs globally apply phonological and orthographic processing in word recognition. If, as suggested by the current data, there is an active interplay between phonology and orthography during reading, one could expect that phonological representations might continue to refine during reading acquisition in CI users. As reading experience increases, more and more precise information about grapho-phonemic correspondence should become available, and the bootstrapping mechanism that takes place between phonological decoding and orthographic coding in TH children should further strengthen phonological representations. One prediction of the current results would hence be that phonological perception should improve along with reading performance over time.

The current results also reconcile seemingly inconsistent findings. That children with CI exhibited both a deficit in auditory phonemic categorization and an orthographic compensation when reading could explain why a word recognition deficit is in principle hard to establish in these children (Archbold et al., 2008; Dillon et al., 2012; Fagan et al., 2007; Geers, 2003; Harris \& Terlektsi, 2011; Spencer \& Tomblin, 2009). In-homogenous reading trajectories in children who use a CI might reflect cumulated inter-individual variability in the primary phoneme perception deficit and in the way they achieve the secondary orthographic compensation.

While shedding some light on inconsistent findings about speech and reading in children with a CI, the current findings also offer practical implications. If the reading deficit in deaf children who use a CI is primarily related to less accurate phonological representations, one way of improving reading could be to foster the development of unambiguous phonological units in their lexicon by for instance using cued speech in the initial auditory recovery phase. Early exposure to audio-visual speech is critical to develop balanced speech perception multi-modal brain networks (Schorr, Fox, van Wassenhove, \& Knudsen, 2005). Accordingly, we and others previously showed that early and intensive exposure to cued speech enhances speech perception (Leybaert \& LaSasso, 2010), phonemic awareness and reading skills in children with a CI (Bouton et al., 2011; Colin et al., 2010). Once phonological representations become sufficiently accurate, children could progressively switch to purely auditory speech learning. Despite promising first results, more research is required to confirm the benefit cued speech might provide in the development of primary linguistic competence of CI users, and whether the speech perception level attained could have a positive impact on reading acquisition.

\section{Acknowledgements}

We thank Valérian Chambon and Jennifer Martin for their comments on the manuscript; Marina Yao-N'dré, Stéphanie Riès, Éléonore Ardiale, Pauline Ayora, Kim Uittenhove, Soazig Casteau and Suzanne Hodzik for useful discussions.

\section{Disclosure statement}

No potential conflict of interest was reported by the authors.

\section{Funding}

SB was supported by a scholarship from the French Ministry of Research; SB and ALG are funded by the European Research Council for the Compuslang Project [Grant agreement 260347] and by the Swiss National Fund [Project Number 320030 149319]. WS was supported by a public grant overseen by the French National Research Agency (ANR) as part of the 'Investissements d'Avenir' programme [reference: ANR-10-LABX-0083].

\section{References}

Ahissar, M. (2007). Dyslexia and the anchoring-deficit hypothesis. Trends in Cognitive Sciences, 11, 458-465. doi:10.1016/j.tics. 2007.08.015

Archbold, S., Harris, M., O'Donoghue, G., Nikolopoulos, T., White A., \& Richmond, H. L. (2008). Reading abilities after cochlear implantation: The effect of age at implantation on outcomes at 5 and 7 years after implantation. International Journal of Pediatric Otorhinolaryngology, 72, 1471-1478. doi:10.1016/j.ijporl.2008.06.016

Banai, K., Hornickel, J., Skoe, E., Nicol, T., Zecker, S. G., \& Kraus, N. (2009). Reading and subcortical auditory function. Cerebral Cortex, 19, 2699-2707. doi:10.1093/cercor/bhp024

Berent, I., Lennertz, T., \& Balaban, E. (2012). Language universals and misidentification: A two-way street. Language and Speech, 55, 311-330. doi:10.1177/0023830911417804

Bernstein, L. E. (1983). Perceptual development for labeling words varying in voice onset time and fundamental-frequency. Journal of Phonetics, 11, 383-393.

Boets, B., Op de Beeck, H. P., Vandermosten, M., Scott, S. K., Gillebert, C. R., Mantini, D., ... Ghesquière, P. (2013). Intact but less accessible phonetic representations in adults with dyslexia. Science, 342, 1251-1254. doi:10.1126/science.12 44333

Bogliotti, C. (2003). Relation between categorical perception of speech and reading acquisition. In M. J. Solé, D. Recaesens, \& J. Romero (Eds.), Proceedings of the 15th international Congress of phonetic science (pp. 885-888). Barcelona: Universitat Autònoma de Barcelona.

Bogliotti, C., Serniclaes, W., Messaoud-Galusi, S., \& SprengerCharolles, L. (2008). Discrimination of speech sounds by children with dyslexia: Comparisons with chronological age and reading level controls. Journal of Experimental Child Psychology, 101, 137-155. doi:10.1016/j.jecp.2008.03.006

Boersma, P., \& Weenink, D. (2000). Praat: Doing phonetics by computer. Available from http://www.praat.org

Bouton, S., Serniclaes, W., Bertoncini J., \& Colé, P. (2012). Categorical perception of speech sounds in French-speaking children with cochlear implant. Journal of Speech, Language and Hearing Research, 55, 139-153. doi:10.1044/1092-4388 (2011/10-0330)

Bouton, S., Bertoncini, J., Serniclaes, W., \& Colé, P. (2011). Reading and reading related skills in children using cochlear implants: Prospects for the influence of cued speech. Journal of 
Deaf Studies and Deaf Education, 16, 458-473. doi:10.1093/ deafed/enr014

Burnham, D. (2003). Language specific speech perception and the onset of reading. Reading and Writing, 16, 573-609. doi:10.1023/A:1025593911070

Burnham, D. K., Earnshaw, L. J., \& Clark, J. E. (1991). Development of categorical identification of native and non native bilabial stops: Infants, children and adults. Journal of Child Language, 18, 231-260. doi:10.1017/S03050009000 11041

Chiappe, P., Chiappe, D. L., \& Siegel, L. S. (2001). Speech perception, lexicality, and reading skill. Journal of Experimental Child Psychology, 80(1), 58-74. doi:10.1006/jecp. 2000.2624

Colin, S., Lina-Granade, G., Truy, E., Ecalle, J., Pénillard, A., \& Magnan, A. (2010). Reading abilities in deaf children: Respective and/or combined contribution of early age of cochlear implantation and exposition to cued speech. Cochlear Implants international, 11(Suppl. 1), 278-281. doi:10.1179/146701010X12671177989192

Content, A., \& Radeau, M. (1988). Données statistiques sur la structure orthographique du Français [Statistical data on spelling structure of French]. Cahiers de Psychologie Cognitive, 87, 399-404.

Dillon, C. M., de Jong, K., \& Pisoni, D. B. (2012). Phonological awareness, reading skills, and vocabulary knowledge in children who use cochlear implants. Journal of Deaf Studies and Deaf Education, 17, 205-226. doi:10.1093/deafed/ enr043

Dorman, M., Loizou, P., Spahr, A., \& Maloff, E. (2002). Factors that allow a high level of speech understanding by patients fit with cochlear implants. American Journal of Audiology, 11(2), 119-123. doi:10.1044/1059-0889(2002/014)

Dunn, C. C., Walker, E., Oleson, J., Kenworthy, M., Van Voorst, T., Tomblin, J.B., ... Gantz, B. J. (2014). Longitudinal development of speech perception and language performance in pediatric cochlear implant users: The effect of age at implantation and long term outcomes. Ear and Hearing, 35, 148-160. doi:10.1097/AUD.0b013e3182a4a8f0

Fagan, M. K., Pisoni, D. B., Horn, D. L., \& Dillon, C. M. (2007). Neuropsychological correlates of vocabulary, reading, and working memory in deaf children with cochlear implants. Journal of Deaf Studies and Deaf Education, 12, 461-471. doi:10.1093/deafed/enm023

Friesen, L. M., Shannon, R. V., Baskent, D., \& Wang, X. (2001). Speech recognition in noise as a function of the number of spectral channels: Comparison of acoustic hearing and cochlear implants. The Journal of the Acoustical Society of America, 110, 1150-1163. doi:10.1121/1.1381538

Friesen, L. M., Shannon, R. V., \& Cruz, R. J. (2005). Effects of stimulation rate on speech recognition with cochlear Implants. Audiology \& Neurotology, 10, 169-184. doi:10.1159/0000 84027

Geers, A. E. (2003). Predictors of reading skill development in children with early cochlear implantation. Ear and Hearing, 24(Suppl.), 59S-68S. doi:10.1097/01.AUD.0000051690.439 $89.5 \mathrm{D}$

Geers, A., Brenner, C., \& Davidson, L. (2003). Factors associated with development of speech perception skills in children implanted by age five. Ear and Hearing, 24 (Suppl. 1), 24S-35S. doi:10.1097/01.AUD.0000051687.99 218.0F

Gnansia, D., Lazard, D. S., Léger, A. C., Fugain, C., Lancelin, D., Meyer, B., \& Lorenzi, C. (2014). Role of slow temporal modulations in speech identification for cochlear implant users. International Journal of Audiology, 53(1), 48-54. doi:10.3109/14992027.2013.844367

Goldsworthy, R. L., Delhorne, L. A., Braida, L. D., \& Reed, C. M. (2013). Psychoacoustic and phoneme identification measures in cochlear-implant and normal-hearing listeners. Trends in Amplification, 17(1), 27-44. doi:10.1177/1084713813477244

Goswami, U., Ziegler, J., Dalton, L., \& Schneider, W. (2001). Pseudohomophone effects and phonological recoding procedures in reading development in English and German. Journal of Memory \& Language, 45, 648-664. doi:10.1006/jmla. 2001.2790

Green, J. R., Beukelman, D. R., \& Ball, L. J. (2004). Algorithmic estimation of pauses in extended speech samples of dysarthric and typical speech. Journal of Medical Speech-Language Pathology, 12, 149-154.

Harm, M. W., \& Seidenberg, M. S. (1999). Reading acquisition, phonology, and dyslexia: Insights from a connectionist model. Psychological Review, 106, 491-528. doi:10.1037/ 0033-295X.106.3.491

Harm, M. W., \& Seidenberg, M. S. (2004). Computing the meanings of words in reading: Cooperative division of labor between visual and phonological processes. Psychological Review, 111, 662-720. doi:10.1037/0033-295X.111.3.662

Harris, M., \& Terlektsi, E. (2011). Reading and spelling abilities of deaf adolescents with cochlear implants and hearing AIDS. Journal of Deaf Studies and Deaf Education, 16(1), 24-34. doi:10.1093/deafed/enq031

Hasko, S., Groth, K., Bruder, J., Bartling, J., \& Schulte-Körne, G. (2013). The time course of reading processes in children with and without dyslexia: An ERP study. Frontiers in Human Neuroscience, 7, 570. doi:10.3389/fnhum.2013.00570

Havy, M., Nazzi, T., \& Bertoncini, J. (2013). Phonetic processing during the acquisition of new words in 3-to-6-year-old French-speaking deaf children with cochlear implants. Journal of Communication Disorders, 46, 181-192. doi:10.1016/ j.jcomdis.2012.12.002

Hazan, V., \& Barrett, S. (2000). The development of phonemic categorization in children aged 6-12. Journal of Phonetics, 28, 377-396. doi:10.1006/jpho.2000.0121

Hoonhorst, I., Colin, C., Markessis, E., Radeau, M., Deltenre, P., \& Serniclaes, W. (2009). French native speakers in the making: From language-general to language-specific voicing boundaries. Journal of Experimental Child Psychology, 104, 353-366. doi:10.1016/j.jecp.2009.07.005

Hoonhorst, I., Medina, V., Colin, C., Markessis, E., Radeau, M., Deltenre, P., \& Serniclaes, W. (2011). Categorical perception of voicing, colors and facial expressions: A developmental study. Speech Communication, 53, 417-430. doi:10.1016/j. specom.2010.11.005

Hornickel, J., Anderson, S., Skoe, E., Yi, H.-G., \& Kraus, N. (2012). Subcortical representation of speech fine structure relates to reading ability, NeuroReport, 23(1), 6-9. doi:10.1097/WNR.0b013e32834d2ffd

Iverson, P. (2003). Evaluating the function of phonetic perceptual phenomena within speech recognition: An examination of the perception of $/ \mathrm{d} /-/ \mathrm{t} /$ by adult cochlear implant users. Journal of the Acoustical Society of America, 113, 10561064. doi:10.1121/1.1531985

Iverson, P. \& Kuhl, P. K. (1996). Influences of phonetic identification and category goodness on American listeners' perception of /r/ and /1/. Journal of the Acoustical Society of America, 99, 1130-1140.

Kral, A., \& Sharma, A. (2012). Developmental neuroplasticity after cochlear implantation. Trends in Neurosciences, 35, 111-122. doi:10.1016/j.tins.2011.09.004 
Kraus, N., \& Anderson, S. (2013). For reading development, auditory processing is fundamental. The Hearing Journal, 66 (9), 40. doi:10.1097/01.HJ.0000434625.54514.1d

Lane, H., Denny, M., Guenther, F., Hanson, H., Marrone, N., Matthies, M., ... Zandipour, M. (2007). On the structure of phoneme categories in listeners with cochlear implants. Journal of Speech, Language and Hearing Research, 50(1), 2-14. doi:10.1044/1092-4388(2007/001)

Lazard, D. S., Lee, H. J., Truy, E., \& Giraud, A.-L. (2013). Bilateral reorganization of posterior temporal cortices in post-lingual deafness and its relation to cochlear implant outcome. Human Brain Mapping, 34, 1208-1219.

Lefavrais, P. (1967). Test de l'Alouette: Manuel [Alouette: A standardized reading test]. Paris: Les Editions du Centre de Psychologie Appliquée.

Lété, B., Sprenger-Charolles, L., \& Colé, P. (2004). MANULEX: A grade-level lexical database from French elementary school readers. Behavior Research Methods, Instruments and Computers, 36, 156-166.

Leybaert, J., \& LaSasso, C. J. (2010). Cued speech for enhancing speech perception and first language development of children with cochlear implants. Trends in Amplification, 14(2), 96-112. doi:10.1177/1084713810375567

Loizou, P. C. (1998). Mimicking the human ear. IEEE Signal Processing Magazine, 15(5), 101-130. doi:10.1109/79.708543

Loizou, P. C. (2006). Speech processing in vocoder-centric cochlear implants. Advances in Oto-Rhino-Laryngology, 64, 109-143.

Macmillan, N. A. \& Creelman, C. D. (1991). Detection theory: A user's guide. New York: Cambridge University Press.

Macmillan, N. A., \& Creelman, C. (2005). Detection theory: A user's guide. London: Lawrence Erlbaum.

Medina, M., Hoonhorst, I., Bogliotti, C., \& Serniclaes, W. (2010). Development of voicing perception in French: Comparing adults, adolescents and children. Journal of Phonetics, 38, 493-503. doi:10.1016/j.wocn.2010.06.002

Medina, V., \& Serniclaes, W. (2009). Consecuencias de la categorización fonológica sobre la lectura silenciosa de niños sordos con implante coclear [Results of phonological categorization on silent reading in children using cochlear implants]. Revista de Logopedia, Foniatría y Audiología, 29, $186-194$.

Mousty, P., \& Leybaert, J. (1999). Evaluation des habilités de lecture et d'orthographe au moyen de BELEC: Données longitudinales auprès d'enfants francophones testés en 2ème et 4ème années [Evaluation of reading and spelling ability by means of the BELEC]. Revue Européenne de Psychologie Appliquée, 4, 325-342.

Nittrouer, S. (1992). Age-related differences in perceptual effects of formant transitions within syllables and across syllable boundaries. Journal of Phonetics, 20, 1-32.

Nittrouer, S. (1996). Discriminability and perceptual weighting of some acoustic cues to speech perception by 3-year-olds. Journal of Speech Language and Hearing Research, 39, 278-297. doi:10.1044/jshr.3902.278

Nittrouer, S. (2002). Learning to perceive speech: How fricative perception changes, and how it stays the same. Journal of the Acoustical Society of America, 112, 711-719. doi:10.1121/ 1.1496082

Nittrouer, S., \& Miller, M. E. (1997). Predicting developmental shifts in perceptual weighting schemes. Journal of the Acoustical Society of America, 101, 2253-2266. doi:10.1121/ 1.418207

Noordenbos, M. W., Segers, E., Serniclaes, W., Mitterer, H., \& Verhoeven, L. (2012). Allophonic mode of speech perception in children at risk for dyslexia: A longitudinal study.
Research in Developmental Disabilities, 33, 1469-1483. doi:10.1016/j.ridd.2012.03.021

Perry, C., Ziegler, J. C., \& Zorzi, M. (2007). Nested incremental modeling in the development of computational theories: The CDP + model of reading aloud. Psychological Review, 114, 273-315. doi:10.1037/0033-295X.114.2.273

Perry, C., Ziegler, J. C., \& Zorzi, M. (2010). Beyond single syllables: Large-scale modeling of reading aloud with the connectionist dual process $(\mathrm{CDP}++)$ model. Cognitive Psychology, 61, 106-151. doi:10.1016/j.cogpsych.2010. 04.001

Pothier, B., \& Pothier, P. (2004). Echelle d'acquisition en orthographe lexicale [Standardized scale of spelling skills]. Paris: Edition Retz.

Ramus, F. (2003). Developmental dyslexia: Specific phonological deficit or general sensorimotor dysfunction? Current Opinion in Neurobiology, 13, 212-218. doi:10.1016/S09594388(03)00035-7

Ramus, F., \& Szenkovits, G. (2008). What phonological deficit? Quarterly Journal of Experimental Psychology, 61(1), 129141. doi:10.1080/17470210701508822

Ripamonti, E., Aggujaro, S., Molteni, F., Zonca, G., Frustaci, M., \& Luzzatti, C. (2014). The anatomical foundations of acquired reading disorders: A neuropsychological verification of the dual-route model of reading. Brain and Language, 134, 44-67. doi:10.1016/j.bandl.2014.04.001

Schorr, E. A., Fox, N. A., van Wassenhove, V., \& Knudsen, E. I. (2005). Auditory-visual fusion in speech perception in children with cochlear implants. Proceedings of the National Academy of Sciences, 102, 18748-18750. doi:10.1073/ pnas.0508862102

Serniclaes, W., Van Heghe, S., Mousty, P., Carré, R., \& Sprenger-Charolles, L. (2004). Allophonic mode of speech perception in dyslexia. Journal of Experimental Child Psychology, 87, 336-361. doi:10.1016/j.jecp.2004.02.001

Shannon, R., Zeng, F., Kamath, V., Wygonski, J., \& Ekelid, M. (1995). Speech recognition with primarily temporal cues. Science, 270, 303-304. doi:10.1126/science.270.5234.303

Share, D. L. (1995). Phonological recoding and self-teaching: Sine qua non of reading acquisition. Cognition, 55, 151-218. doi:10.1016/0010-0277(94)00645-2

Share, D. L. (1999). Phonological recoding and orthographic learning: A direct test of the self-teaching hypothesis. Journal of Experimental Child Psychology, 72, 95-129. doi:10.1006/jecp.1998.2481

Sharma, A., Campbell, J., \& Gordon, G. (in press). Developmental and cross-modal plasticity in deafness: Evidence from the $\mathrm{P} 1$ and $\mathrm{N} 1$ event related potentials in cochlear implanted children. International Journal of Psychophysiology.

Sharma, A., Dorman, M. F., \& Kral, A. (2005). The influence of a sensitive period on central auditory development in children with unilateral and bilateral cochlear implants. Hearing Research, 203(1-2), 134-143. doi:10.1016/j. heares.2004.12.010

Slawinski, E. B., \& Fitzgerald, L. K. (1998). Perceptual development of the categorization of the / r-w / contrast in normal children. Journal of Phonetics, 26(1), 27-43. doi:10.1006/ jpho. 1997.0057

Snowling, M. J. (2000). Dyslexia (2nd ed.). Oxford: Blackwell.

Spencer, L. J., \& Tomblin, J. B. (2009). Evaluating phonological processing skills in children with prelingual deafness who use cochlear implants. Journal of Deaf Studies and Deaf Education, 14(1), 1-21. doi:10.1093/deafed/enn013

Sprenger-Charolles, L., Colé, P., Béchennec, D., \& KipfferPiquard, A. (2005). Lecture et compétences reliées: Données normatives pour la fin de la 1ère, 2nde, 3ème et 4ème année 
du primaire issues d'une nouvelle batterie de tests, EVALEC [Standardized norms on the development of reading and related skills in French, EVALEC]. European Review of Applied Psychology/Revue Europeenne de Psychologie Appliquée, 55, 157-186.

Sprenger-Charolles, L., Colé, P., \& Serniclaes, W. (2006). Reading acquisition and developmental dyslexia. London: Psychology Press.

Sprenger-Charolles, L., Siegel, L.S., Béchennec, D., \& Serniclaes, W. (2003). Development of phonological and orthographic processing in reading aloud, in silent reading, and in spelling: A four-year longitudinal study. Journal of Experimental Child Psychology, 84, 194-217. doi:10.1016/S00220965(03)00024-9

Tye-Murray, N., Spencer, L., \& Gilbert-Bedia, E. (1995). Relationships between speech production and speech perception skills in young cochlear-implant users. The Journal of the Acoustical Society of America, 98, 2454-2460. doi:10.1121/1.413278

Vandermosten, M., Boets, B., Luts, H., Poelmans, H., Wouters, J., \& Ghesquière, P. (2011). Impairments in speech and nonspeech sound categorization in children with dyslexia are driven by temporal processing difficulties. Research in Developmental Disabilities, 32, 593-603. doi:10.1016/j.ridd.2010.12.015

Vellutino, F. R., Fletcher, J. M., Snowling, M. J., \& Scanlon, D. M. (2004). Specific reading disability (dyslexia): What have we learned in the past four decades? Journal of Child Psychology and Psychiatry, 45(1), 2-40. doi:10.1046/j.00219630.2003.00305x
Vermeulen, A. M., Van Bon, W., Schreuder, R., Knoors, H., \& Snik, A. (2007). Reading comprehension of deaf children with cochlear implants. Journal of Deaf Studies and Deaf Education, 12, 283-302. doi:10.1093/deafed/enm017

Wible, B., Nicol, T, \& Kraus, N. (2004). Atypical brainstem representation of onset and formant structure of speech sounds in children with language-based learning problems. Biological Psychology, 67, 299-317. doi:10.1016/j. biopsycho.2004.02.002

$\mathrm{Xu}$, L., \& Zheng, Y. (2007). Spectral and temporal cues for phoneme recognition in noise. The Journal of the Acoustical Society of America, 122, 1758-1764. doi:10.1121/1.2767000

Ziegler, J. C., Jacobs, A., \& Klüppel, D. (2001). Pseudohomophone effects in lexical decision: Still a challenge for current word recognition models. Journal of Experimental Psychology. Human perception and performance, 27, 547-559. doi:10.1037/0096-1523.27.3.547

Ziegler, J. C., Perry, C., \& Zorzi, M. (2014). Modelling reading development through phonological decoding and self-teaching: Implications for dyslexia. Philosophical transactions of the Royal Society of London. Series B, Biological Sciences, $369,1634-1644$.

Ziegler, J. C., Van Orden, G., \& Jacobs, A. (1997). Phonology can help or hurt the perception of print. Journal of Experimental Psychology, Human Perception and Performance, 23, 845-860. doi:10.1037/0096-1523.23.3.845 
Appendix 1. Items of the experimental tasks

Appendix 1.1. Items of minimal pairs for discrimination and identification tasks

\begin{tabular}{llll}
\hline Place of articulation & \multicolumn{1}{c}{ voicing } & \multicolumn{1}{c}{ nasality } & \multicolumn{1}{c}{ manner } \\
\hline bus / buche & seau / zoo & main / nain & cou / choux \\
case / cage & choux / joue & majeur / nageur & $\mathrm{bol} / \mathrm{vol}$ \\
gant / banc & poisson / poison & & $\mathrm{pleurs} \mathrm{/} \mathrm{fleurs}$ \\
tarte / carte & douche / touche & & sable / table \\
bois / doigt & fer / verre & & bouche / mouche \\
\hline
\end{tabular}

Appendix 1.2. Items of pseudoword and irregular word reading task

\begin{tabular}{ll}
\hline Pseudowords & Irregular words \\
\hline cande & compte \\
matore & million \\
pirche & paon \\
sinope & sept \\
atouse & album \\
pogide & piscine \\
simade & sixième \\
bogir & baptême \\
chaful & short \\
paillou & poêle \\
orcine & orchestre \\
affobe & aquarelle \\
atrul & automne \\
corpi & choeur \\
ogibe & oignon \\
ampide & ennui \\
supon & seconde \\
moube & monsieur \\
danepi & dix \\
pitode & pied \\
frante & fils \\
mocile & maximum \\
duche & deuxième \\
pidre & pays \\
vacide & ville \\
quive & chorale \\
fuchi & femme \\
cuifle & clown \\
ocipre & oeil \\
adrile & accident \\
égibe & aiguille \\
sotar & six \\
énoure & écho \\
onfre & août \\
furpe & faon \\
cirate & scie \\
\hline & \\
\hline
\end{tabular}




\section{Appendix 1.3. Items of lexical decision task}

\begin{tabular}{lll}
\hline Control words & Homophone pseudowords & Non-homophone pseudowords \\
\hline dose & déphi & déchi \\
chaise & chace & chisse \\
soupe & sinje & sinpe \\
ride & rouje & roupe \\
fiche & fove & faume \\
vide & vélau & vépo \\
mère & menche & manphe \\
malin & mersi & morci \\
feuille & phoc & phobe \\
loupe & linje & linte \\
filet & fuzée & fulée \\
pile & pègne & peime \\
larme & leine & laipe \\
plume & plaje & plade \\
rouge & raine & reile \\
\hline
\end{tabular}

\section{Appendix 2. Scores on picture-naming task}

Children who use CI

$80.38 \%(20.62)$
Age-matched controls

$100 \%(0)$

Note: Performance for picture naming task. Data are presented in children using cochlear implants (CI), normal-hearing controls matched for chronological age, and normal-hearing controls matched for reading level, as correct responses (\%) and standard deviation in brackets.
Reading age controls $100 \%(0)$ 